\title{
New insights into the functions and regulation of the transcriptional corepressors SMRT and N-CoR Kristopher J Stanya ${ }^{1,2}$ and Hung-Ying Kao*1
}

\author{
Address: ${ }^{1}$ Department of Biochemistry, School of Medicine, Case Western Reserve University and the Research Institute of University Hospitals of \\ Cleveland, 10900 Euclid Avenue, Cleveland, Ohio 44106, USA and ${ }^{2}$ Department of Genetics and Complex Diseases, School of Public Health, \\ Harvard University, 665 Huntington Avenue, Boston, Massachusetts 02215, USA \\ Email: Kristopher J Stanya - kstanya@hsph.harvard.edu; Hung-Ying Kao* - hxk43@case.edu \\ * Corresponding author
}

Published: 21 April 2009

Cell Division 2009, 4:7 doi:10.1 186/1747-1028-4-7
Received: 26 March 2009

Accepted: 21 April 2009

This article is available from: http://www.celldiv.com/content/4/I/7

(c) 2009 Stanya and Kao; licensee BioMed Central Ltd.

This is an Open Access article distributed under the terms of the Creative Commons Attribution License (http://creativecommons.org/licenses/by/2.0), which permits unrestricted use, distribution, and reproduction in any medium, provided the original work is properly cited.

\begin{abstract}
Corepressors are large proteins that facilitate transcriptional repression through recruitment of histone-modifying enzymes. Two major corepressors, SMRT (silencing mediator for retinoid and thyroid hormone receptors) and N-CoR (nuclear receptor corepressor), have been shown to mediate repression associated with nuclear receptors and a myriad of other transcription factors. This review will focus on recent studies on these proteins, including newly discovered physiological roles of the corepressors, their modes of regulation, their roles in antiestrogen-resistant breast cancer and their functions during the cell cycle.
\end{abstract}

\section{SMRT and N-CoR are transcriptional corepressors}

Control of transcription is mediated by many signaling pathways, including small, non-protein steroids. Steroids control transcription by binding to nuclear receptors (NRs) which in turn modulate transcription of target genes. Studies of nuclear receptor signaling has led to the elucidation of basic mechanisms of transcriptional activation, repression and identification of the specific protein families that control these processes (coactivators and corepressors, $[1,2])$. In particular, corepressors mediate the active repression of transcription through recruitment of enzymes to post-translationally modify histone tails. Furthermore, corepressors themselves are subject to regulated control of activity, localization and stability through various intercellular pathways. Corepressors are critical for the treatment of certain breast cancers and may also play important roles in the regulation of mitosis.
The first nuclear receptor corepressors identified, SMRT and $\mathrm{N}$-CoR, were isolated in yeast 2-hybrid screens as interacting partners of retinoid $\mathrm{X}$ or thyroid hormone receptor (RXR, TR) [3-7]. SMRT and N-CoR share approximately $45 \%$ amino acid sequence identity [8] and both are subject to extensive alternative mRNA splicing, generating multiple isoforms [9]. These two corepressors likely share some similar functions while exerting other, distinct influences within cells and organisms. While many interaction partners are shared between the two corepressors, other interaction partners are specific to each corepressor.

\section{Corepressor domains and stable interacting partners}

The corepressors SMRT and N-CoR share similar domain organizations and are believed to be paralogs [8]. Both proteins contain multiple repression domains (RDs), Swi3/Ada2/N-CoR/TFIIID (SANT) motifs [10] and nuclear receptor interaction domains (NRIDs). SANT 
motifs in corepressors have been shown to be histone binding modules $[10,11]$, although specific mechanisms underlying this are unclear. SMRT contains two NRIDs, while N-CoR contains three NRIDs. The NRIDs in each can be removed by alternative splicing. The RDs likely serve as binding platforms for the various silencing enzymes recruited to repress gene promoters, including the histone deacetylases (HDACs). Thus, both SMRT and $\mathrm{N}$-CoR are part of larger complexes. These corepressor complexes can be considered to be large docking surfaces to tether repression machinery to transcription factors.

Both SMRT and N-CoR have been subjected to extensive biochemical purification to identify core components of their respective complexes. Both complexes contain the same core associated factors, including HDAC3, GPS2 (G protein pathway suppressor 2; X. Cheng and H.Y. Kao, unpublished data) and the transducin $\beta$-like factors, TBL1 and TBLR1 [12-16]. These four proteins consistently copurify together with both SMRT and N-CoR. Interaction of HDAC3 with either the SMRT or the N-CoR complex is thought to promote deacetylase activity on histones $[10,13,17]$. Other HDACs also interact with SMRT or NCoR complexes, including class II HDACs 4,5 and 7 [1720] and class I HDACs 1 and 2 (through the corepressor mSin3 (mammalian switch independent 3 protein)] [2123], but their roles in SMRT- and N-CoR-dependent gene repression is unclear. In order to form an active SMRTHDAC3 complex, association with the TRiC-1 (TCP1 ring complex) chaperone is required [24]. This process is ATPdependent and TRiC-1 dissociates from SMRT-HDAC3 following complex formation. Although this requirement has only been demonstrated for SMRT complex formation, it is likely that a similar pathway exists for N-CoR complex formation.

\section{Corepressor-mediated repression}

One major function of SMRT and N-CoR is the repression of gene transcription. This function is modulated in part through deacetylation of lysines on histone tails by histone deacetylases contained in large corepressor complexes. Deacetylated histones may serve as preferred binding sites for corepressor complexes in what has been described as a "feed-forward mechanism" [11]. Current models indicate that corepressor complexes initially recognize acetylated chromatin and deacetylates the histone tails. These complexes may then show increased affinity for the deacetylated chromatin, thus enhancing gene repression by increased association. HDAC3 is hypothesized to be the primary histone deacetylase in SMRT/NCoR complexes. A novel domain termed the deacetylase activating domain (DAD) in both SMRT and N-CoR (located between the two SANT domains) has been shown to promote both the enzymatic activity and binding of HDAC3 [10]. HDAC3 alone targets acetylated lysines on histone $\mathrm{H} 2 \mathrm{~A}$ and lysines $\mathrm{K} 5$ and $\mathrm{K} 12$ of $\mathrm{H} 4$ in vitro [25]; another study reported N-CoR/HDAC3 complexes were specific for $\mathrm{H} 3$ in vitro [26]. This suggests that corepressor complexes direct the substrate specificity of HDAC3. Extending these studies into mammalian cells, it was shown that SMRT/HDAC3-mediated deacetylation was specific for $\mathrm{H} 4$ on the RAR $\gamma 2$ gene [27]. Further work may elucidate the specific roles of the various HDACs in corepressor complexes and identify actual target lysine residues on histone tails.

\section{SMRT and N-CoR have non-overlapping physiological functions}

SMRT knockout mice (SMRT -/- mice) have recently been described $[28,29]$. This gene disruption is an embryonic lethal at approximately embryonic day 16.5 (E16.5) due mainly to defects in cardiogenesis [29]. Specifically, aberrations were observed in ventricular septation and hypoplasia of the ventricular chambers of the heart. The mechanism has been partially delineated as being forkhead box protein 1 (FOXP1) dependent. FOXP1 -/-, SMRT -/- and SMRT +/-/FOXP1 +/- embryos all show similar phenotypes. SMRT and FOXP1 interact in embryonic hearts and colocalize to chromatin to repress target gene transcription [29]. It was further demonstrated that reexpression of $\alpha$-myosin heavy chain promoter-driven SMRT rescued the SMRT -/- heart defects and the animals survived to birth [28]. However, these rescued animals exhibited significant defects in forebrain development, including major deficiencies in the proportional volumes of dorsal and ventral telencephalon regions. Isolated neural progenitor cells from SMRT -/- animals were prone to differentiate into both neurons and glial cells, indicating that SMRT prevents neuronal stem cell self-renewal. This differentiation effect was shown to be both RAR- and retinoic acid-dependent with the underlying mechanism being repression of the JMJD3 histone demethylase. The absence of SMRT activates JMJD3 which in turn activates genes required for neuronal differentiation by demethylating H3K27 tri-methylation [28].

Similar to SMRT -/- mice, knockout of the N-CoR gene in mice (N-CoR -/- mice) is also an embryonic lethal [30]. However, N-CoR deficient mice typically die by E15.5, one day earlier than SMRT -/- embryos. Observed phenotypes include smaller livers, smaller overall size and anemia due to erythropoietic defects. N-CoR -/- embryos also showed defects in T cell development and lower thymocyte counts. Other defects included major aberrations in nervous system development which was hypothesized to be due to increased neural differentiation. This is similar to SMRT -/- animals, although the underlying mechanisms were not studied in detail. Fibroblasts derived from N-CoR -/- animals displayed altered repression of NRdriven luciferase reporters in transfection assays. Together, 
these data indicate that N-CoR controls a plethora of important developmental pathways some of which are independent of SMRT.

Recent work from multiple groups has identified several important physiological roles for SMRT and N-CoR using mutational approaches. Two groups, one deleting the NRIDs of N-CoR [31] and the other mutating the NRIDs of SMRT [32], showed that both corepressors are critical for thyroid control of metabolism. Furthermore, SMRT NRID mutant animals were obese due to spontaneous adipogenesis. N-CoR mutant mice that cannot interact with HDAC3 are lean and have abnormal circadian rhythms [33], indicating that corepressor-mediated repression is critical for both metabolism and normal circadian activities. Together, these animal studies indicate that SMRT and N-CoR are critical for normal mammalian physiology.

\section{Post-translational modifications of corepressors} It is well-established that SMRT and N-CoR repress transcription. Until recently, it was assumed that SMRT and NCoR had overlapping cellular functions since they share both sequence and functional similarity. However, recent work has demonstrated that these two proteins, while sharing some functions, are regulated in unique ways, including distinct patterns of alternative splicing (reviewed in [9]) and post-translational modifications. This idea is supported by the mouse models mentioned previously, indicating that each corepressor is individually required for distinct pathways critical for normal mammalian development.

\section{Phosphorylation of corepressors}

Several studies investigating the transcriptional regulation of NF-kB-controlled genes have identified a role for SMRT repression and a mechanism that relieves SMRT-mediated repression $[34,35]$. SMRT has been shown to repress genes such as ciap-2 and $I L-8$, which are NF- $\mathrm{KB}$ target genes. Initial studies revealed that the IKK $\alpha$ kinase is recruited to chromatin in response to various stimuli where it phosphorylates SMRT at Ser2410. This phosphorylated site serves as a recognition motif for the 14-3-3e signaling protein, which exports SMRT out of the nucleus leading to proteasome-mediated degradation. This translocation results in activation of the ciap- 2 and $I L-8$ genes [34].

In addition to IKK $\alpha$, SMRT is subject to phosphorylation by other kinases, including casein kinase 2 (CK2), epidermal growth factor receptor (EGFR), mitogen-activated protein kinase-related pathways (MAPK) and calmodulindependent protein kinase IV (CamKIV). Due to a shift in the electrophoretic mobility of SMRT in response to transforming growth factor $\beta$ (TGF $\beta$ ) treatment in several cell lines, various kinase pathways were investigated to identify the source of the shift [36]. CK2, a downstream effec- tor of TGF $\beta$, was found to be the relevant SMRT-targeting kinase. CK2 phosphorylates SMRT on Ser1492 which stabilizes the association between SMRT and NRs and thus enhances repression.

When cells were cotransfected with v-erbB, a constitutively active form of the EGFR (epidermal growth factor receptor), TR-mediated SMRT-dependent repression was abolished with little effect on TR-mediated gene activation [37]. This was due to a loss of interaction between SMRT and TR. It is likely that v-erbB phosphorylates multiple sites on SMRT, as these derepression effects were manifested over the whole protein rather than just the NR boxes that mediate TR binding.

Several studies have identified MAPK signaling as inhibitory to SMRT-mediated repression. The MAPK MEKK1 was shown to phosphorylate SMRT and induce nuclear export of SMRT, thus de-repressing target genes [38]. Further studies established that this signaling was unique to SMRT, as N-CoR remained localized in the nucleus in response to MEKK1 expression [39]. A similar mechanism was shown for SMRT phosphorylation by CamKIV in response to cell stimulation, such as $\mathrm{Ca}^{2+}$ release in neurons [40]. It was further demonstrated that protein phosphatase 1 could dephosphorylate SMRT to induce nuclear retention and promote repression of target genes [40].

SMRT has been shown to co-purify with DNA protein kinase (DNA-PK) and other DNA repair complex components such as Ku70 and Ku80 [41]. Interestingly, Ku70 was shown to recruit SMRT to DNA to repress transcription and this appears to be specific for SMRT and not NCoR. Furthermore, knockdown of SMRT, but not N-CoR sensitized cells to DNA damage, indicating a potential role for SMRT in DNA damage repair. It is not clear whether DNA-PK phosphorylates SMRT in this pathway.

Few N-CoR-targeting kinases have been identified. Using biochemical methods, DNA-PK was identified in the NCoR complex and was shown to phosphorylate HDAC3 which inhibits N-CoR-dependent repression [42]. Additionally, Ku70, Ku86 and PARP1 (poly(ADP-ribose) polymerase 1) were also identified in the complex, although not examined in detail. This report, along with the observation that SMRT, but not N-CoR, is required for Ku70-dependent DNA repair [41], suggests that N-CoR either sequesters DNA repair proteins or that complexes containing N-CoR and Ku70 have an as-yet undetermined function. Exploration of this mechanism may reveal further differences between SMRT and N-CoR signaling.

\section{Degradation of corepressors}

Several studies have explored the mechanisms controlling the stability of N-CoR and SMRT. Using the N-terminal region of $\mathrm{N}-\mathrm{CoR}$ as bait in a yeast 2-hybrid screen, the $\mathrm{E} 3$ 
ubiquitin ligase mSiah2 was identified as an N-CoR-interacting protein [43]. mSiah2 was shown to target N-CoR for proteasomal degradation in addition to reversing $\mathrm{N}$ CoR-mediated transcriptional repression (Figure 1). This effect was specific to N-CoR, as no degradation of SMRT was observed. In another study it was observed that estrogen treatment decreased N-CoR protein levels, but not NCoR mRNA [44]. Estrogen treatment up-regulates both mSiah2 mRNA and protein levels likely resulting in degradation of N-CoR. The degradation could be reversed by treatment with the proteasome inhibitor MG132 or siRNA targeting mSiah2. This mechanism was identified as a novel pathway to activate ER-regulated genes such as 24-hydroxylase.

We have recently identified a novel pathway targeting SMRT for degradation [45]. The peptidyl-prolyl isomerase Pin 1 was shown to be a SMRT-interacting protein by yeast 2-hybrid screening. Pin1 binds substrates at phosphorylated serine-proline or threonine-proline dipeptide motifs (pS-P or pT-P) and isomerizes proline motifs from cis to trans (or trans to cis). We found that the cyclindependent kinase Cdk2 phosphorylates SMRT to generate Pin 1 binding sites. Upon binding these sites, Pin 1 likely induces conformational changes in SMRT via proline isomerization. Together, Cdk2 and Pin 1 promote degradation of SMRT (Figure 1). Neither Cdk2 nor Pin1 coimmunoprecipitated N-CoR, indicating that this pathway is specific for SMRT, as the Siah2 pathway is for N-CoR. Furthermore, both Cdk2 activity and Pin 1 levels are positively regulated by the tyrosine kinase receptor Her2/neu/ ErbB2. Together, our results indicate that the stability of a corepressor protein can be regulated through a membrane receptor-dependent pathway; this pathway also has important implications in tamoxifen-resistant breast cancers, as discussed below.

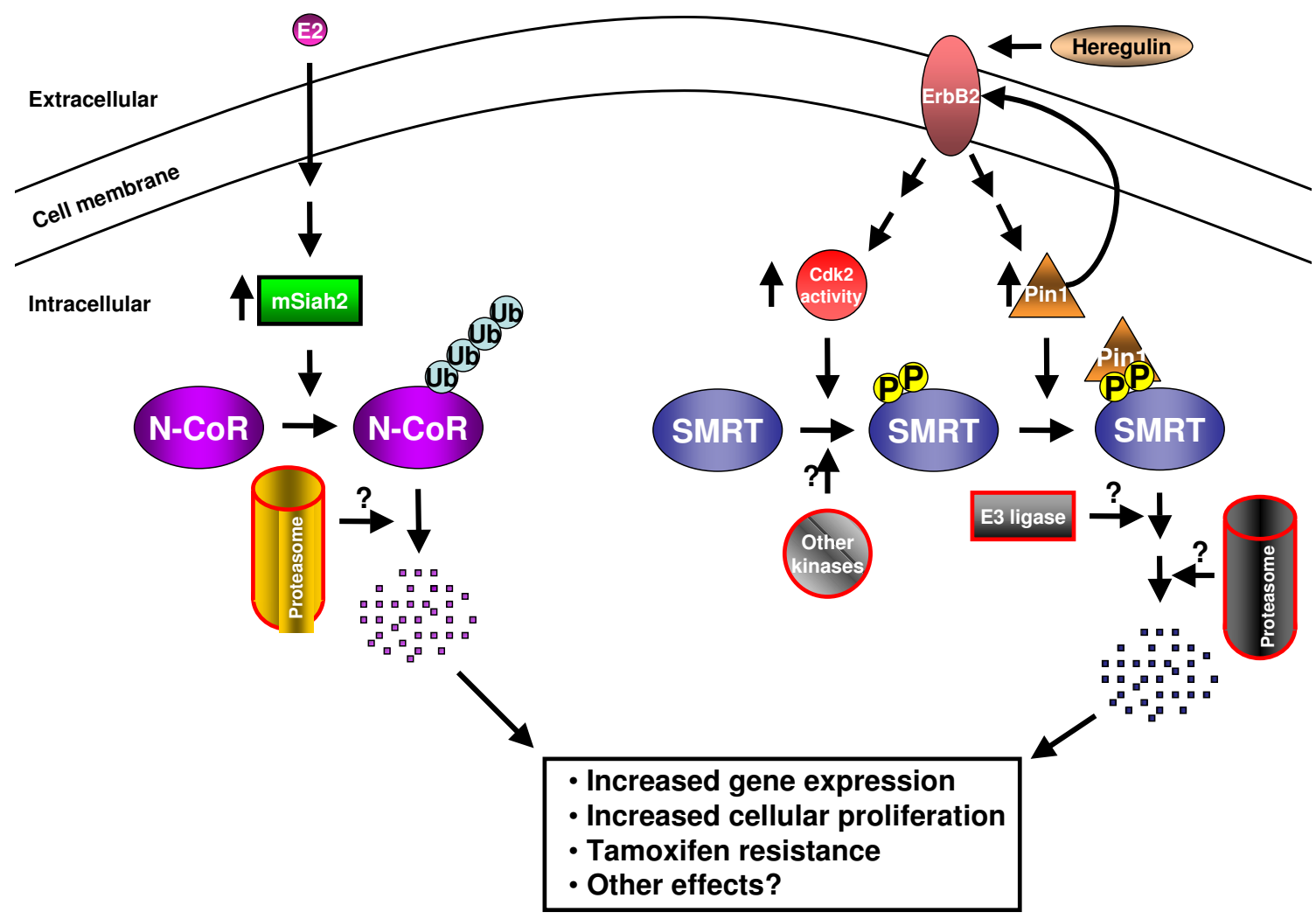

Figure I

Degradation of pathways for SMRT and N-CoR. SMRT and N-CoR are subject to unique degradation pathways. Estrogen (E2) increases mRNA levels of the E3 ubiquitin ligase mSiah2. mSiah2 targets N-CoR for degradation by the proteasome. SMRT is degraded by a distinct pathway. SMRT is phosphorylated by Cyclin-dependent kinase 2 (Cdk2) and potentially other kinases. Phosphorylated SMRT then serves as a substrate for the peptidyl-prolyl isomerase Pin I which alters the conformation of its substrate. Both Pin I levels and Cdk activity are increased by the oncoprotein ErbB2; furthermore, Pin I can increase ErbB2 activity. SMRT is then degraded, likely by subsequent ubiquitination and targeting to the proteasome. Loss of corepressors likely increases transcription of target genes, including some involved in proliferation. Corepressor degradation also likely contributes to tamoxifen resistance. 


\section{Corepressors and breast cancer}

The majority of breast cancer tumors express ER $\alpha$. Drugs that target ER $\alpha$ have been a mainstay of breast cancer treatment for nearly 50 years, yet many of the signaling pathways that underlie such treatments remain incompletely understood. This especially pertains to the selective estrogen receptor modulator (SERM) tamoxifen, which remains an important agent in the treatment of ER $\alpha$-positive breast cancer. Tamoxifen is the major drug used for early stage and advanced premenopausal ER $\alpha$ positive breast cancer and for prevention of breast cancer in both younger and older women at high risk for developing the disease. Tamoxifen recruits corepressors SMRT and N-CoR to dimerized estrogen receptors [46]. Binding of these corepressors to ER $\alpha$ results in repression of ER $\alpha$ target genes, including those involved in cell proliferation, through modification of histones and concomitant chromatin remodeling to a more compact state. Thus, corepressor levels are critical for tamoxifen-mediated transcriptional repression and its anti-proliferative activity $[47,48]$. However, alterations in the balance between coactivators and corepressors can switch tamoxifen from an antagonist to an agonist of ER $\alpha$-dependent gene expression [49]. Imbalance in the coactivator to corepressor ratio is hypothesized to be a major contributor to tamoxifen resistance in breast cancer (Figure 2). Breast cancer patients that are both ER $\alpha$-positive and ErbB2-positive are resistant to tamoxifen therapy. Our data strongly

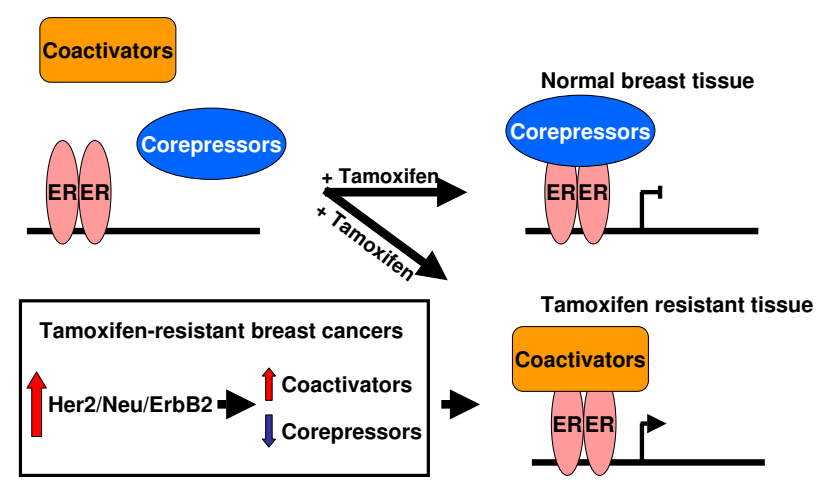

Figure 2

Corepressors and tamoxifen-resistant breastcancers. Estrogen receptors (ER) can interact with either coactivators or corepressors. Tamoxifen, a common treatment for ER $\alpha$-positive breast cancers, induces an ER $\alpha$ conformational change that favors recruitment of corepressors to repress proliferative genes controlled by ER $\alpha$. However, some breast cancers show ER $\alpha$ recruitment of coactivators even in the presence of tamoxifen, thus resulting in activation of proliferative genes. Many of these tamoxifen-resistant breast cancers overexpress the oncogene ErbB2, which has been shown to increase coactivator levels and decrease corepressor levels, thus altering the delicate ratio between these critical factors. suggest that inhibition of Cdk2 and/or Pin1 in ER $\alpha$-positive and ErbB2-positive breast cancer cells will enhance the anti-tumor activity of tamoxifen.

ErbB2 has been shown to act upstream of both Cdk2 and Pin1. ErbB2 activates the E2F family of transcription factors which in turn increase transcription of both Pin 1 [50] and Cyclins A and E [51], both of which are activating factors for Cdk2. Activation of Cdk2 has been implicated in anti-estrogen (tamoxifen) resistance [52]. Pin1 overexpression is prevalent in many different cancers including breast cancer [53] and there is strong correlation between its overexpression and breast cancer in patients $[53,54]$. Furthermore, Pin 1 has recently been shown to stabilize ErbB2 [55], thus completing a positive feedback loop.

ErbB2 is also overexpressed in some ER $\alpha$-negative breast cancers and prostate cancers. Androgen receptor (AR) is an essential component in androgen-dependent prostate cancer. Similar to $\mathrm{ER} \alpha$, androgen receptor can employ SMRT and N-CoR to repress target genes. Furthermore, overexpression of SMRT or restoring the association of SMRT with AR on AR target genes by MEK inhibitors correlates with the ability of antiandrogens to inhibit prostate cancer cell growth [56]. Therefore, identification of SMRT as a downstream target of ErbB2 that plays a critical role in transcriptional regulation will help develop therapeutic agents for ErbB2-positive cancer patients, such as screening small molecule(s) that increase SMRT protein levels.

\section{Potential roles for corepressors in cell cycle regulation}

While neither SMRT nor N-CoR have been assigned a direct role in regulating the cell cycle, SMRT levels have been reported to fluctuate during mitosis [4]. Knockdown of both SMRT and N-CoR by siRNA increased cell proliferation rates in MCF7 cells [57] while our data indicated SMRT knockdown alone was sufficient to increase proliferation rates in BT474 cells [45]. Furthermore, both Cdk2 and Pin 1 are established cell cycle-regulating enzymes $[58,59]$.

Several recent reports have identified a novel role for HDAC3 in cell cycle regulation. In terms of transcriptional regulation, HDAC3 has been shown to repress several critical cell cycle regulators such as the E3 ubiquitin ligase Skp2 [60,61] and several Cdk inhibitors [62]. In addition to transcriptional repression, HDAC3 deacetylates $\mathrm{H} 3$ localized at centromeres [63] and facilitates Aurora B recruitment to phosphorylate $\mathrm{H} 3$, a required histone modification to proceed through mitosis [64]. HDAC3 has also been shown to localize to the mitotic spindle [65], although its function there remains unknown. Since SMRT is critical for HDAC3 deacetylase activity, we specu- 
late that SMRT may also be important for these activities and thus critical for normal cell cycle progression.

Both whole animal and targeted deletion of HDAC3 suggest a role for this enzyme in cell cycle regulation. HDAC3 -/- MEFs (mouse embryonic fibroblasts) show delayed cell cycling, higher levels of DNA damage and increased apoptosis [66]. Targeted deletion of HDAC3 in either heart [67] or liver [68] resulted in organ hypertrophy that may be attributed to increased proliferation. Together, HDACs and their associated corepressor complexes have been identified as potentially important targets in treating various cancers [69], although further study is necessary to elucidate the mechanisms underlying the roles of these corepressors in cell cycle regulation.

\section{Concluding remarks}

Since the isolation of the transcriptional corepressors SMRT and N-CoR more than ten years ago, the major focus has been their respective roles in transcriptional regulation. These biochemical and molecular studies have established how these two large platform proteins function in many cellular processes. In addition, recent animal and cellular studies have further advanced our understanding of the physiological function and regulation of SMRT and N-CoR. However, we believe that we are only beginning to elucidate the complex regulatory network and biological activity of these two proteins. As SMRT and $\mathrm{N}$-CoR play important roles in animal development, homeostasis and are also associated with human diseases, elucidation of the mechanisms and upstream signaling controlling their activities is critical.

Several important avenues remain unexplored. For example, if HDAC3 is a stable component of SMRT and N-CoR corepressor complexes and a critical regulator of the cell cycle, are SMRT or N-CoR also critical for HDAC3-mediated cell cycle progression? Is SMRT or N-CoR regulated in a cell cycle-dependent manner? How do SMRT and N-CoR contribute to DNA damage repair and how do post-translational modifications control stability of these two corepressors? These questions warrant future investigation.

\section{Competing interests}

The authors declare that they have no competing interests.

\section{Authors' contributions}

KJS and HYK drafted the manuscript.

\section{Acknowledgements}

We would like to thank Drs. E. Reineke and D. Samols for critical comments on the manuscript. H.Y. Kao is supported by Pardee Foundation, American Cancer Society, and NIH (DK078965).

\section{References}

I. Sonoda J, Pei L, Evans RM: Nuclear receptors: decoding metabolic disease. FEBS Lett 2008, 582(1):2-9.

2. Nagy L, Schwabe JW: Mechanism of the nuclear receptor molecular switch. Trends Biochem Sci 2004, 29(6):317-24.

3. Sande S, Privalsky ML: Identification of TRACs (T3 receptorassociating cofactors), a family of cofactors that associate with, and modulate the activity of, nuclear hormone receptors. Mol Endocrinol 1996, 10(7):813-25.

4. Park EJ, Schroen DJ, Yang M, Li H, Li L, Chen JD: SMRTe, a silencing mediator for retinoid and thyroid hormone receptorsextended isoform that is more related to the nuclear receptor corepressor. Proc Natl Acad Sci USA 1999, 96(7):3519-24.

5. Ordentlich P, Downes M, Xie W, Genin A, Spinner NB, Evans RM: Unique forms of human and mouse nuclear receptor corepressor SMRT. Proc Natl Acad Sci USA 1999, 96(6):2639-44.

6. Chen JD, Evans RM: A transcriptional co-repressor that interacts with nuclear hormone receptors. Nature 1995, 377(6548):454-7.

7. Horlein AJ, Naar AM, Heinzel T, Torchia J, Gloss B, Kurokawa R, Ryan A, Kamei Y, Soderstrom M, Glass CK, Rosenfeld MG: Ligandindependent repression by the thyroid hormone receptor mediated by a nuclear receptor co-repressor. Nature 1995, 377(6548):397-404.

8. Privalsky ML: The role of corepressors in transcriptional regulation by nuclear hormone receptors. Annu Rev Physiol 2004, 66:315-60.

9. Goodson M, Jonas BA, Privalsky MA: Corepressors: custom tailoring and alterations while you wait. Nucl Recept Signal 2005, 3:e003.

10. Guenther MG, Barak O, Lazar MA: The SMRT and N-CoR corepressors are activating cofactors for histone deacetylase 3. Mol Cell Biol 200I, 2I( I8):609I-I0I.

II. Yu J, Li Y, Ishizuka T, Guenther MG, Lazar MA: A SANT motif in the SMRT corepressor interprets the histone code and promotes histone deacetylation. Embo J 2003, 22(13):3403-10.

12. Zhang J, Kalkum M, Chait BT, Roeder RG: The N-CoR-HDAC3 nuclear receptor corepressor complex inhibits the JNK pathway through the integral subunit GPS2. Mol Cell 2002, 9(3):6II-23.

13. Yoon HG, Chan DW, Huang ZQ, Li J, Fondell JD, Qin J, Wong J: Purification and functional characterization of the human N-CoR complex: the roles of HDAC3, TBLI and TBLRI. Embo J 2003, 22(6): 1336-46.

14. Li J, Wang J, Nawaz Z, Liu JM, Qin J, Wong J: Both corepressor proteins SMRT and N-CoR exist in large protein complexes containing HDAC3. Embo J 2000, 19(16):4342-50.

15. Guenther MG, Lane WS, Fischle W, Verdin E, Lazar MA, Shiekhattar R: A core SMRT corepressor complex containing HDAC3 and TBLI, a WD40-repeat protein linked to deafness. Genes Dev 2000, I 4(9): 1048-57.

16. Perissi V, Aggarwal A, Glass CK, Rose DW, Rosenfeld MG: A corepressor/coactivator exchange complex required for transcriptional activation by nuclear receptors and other regulated transcription factors. Cell 2004, I I 6(4):5 I I-26.

17. Fischle W, Dequiedt F, Hendzel MJ, Guenther MG, Lazar MA, Voelter W, Verdin E: Enzymatic activity associated with class II HDACs is dependent on a multiprotein complex containing HDAC3 and SMRT/N-CoR. Mol Cell 2002, 9(I):45-57.

18. Fischle W, Dequiedt F, Fillion M, Hendzel MJ, Voelter W, Verdin E: Human HDAC7 histone deacetylase activity is associated with HDAC3 in vivo. J Biol Chem 200I, 276(38):35826-35.

19. Huang EY, Zhang J, Miska EA, Guenther MG, Kouzarides T, Lazar MA: Nuclear receptor corepressors partner with class II histone deacetylases in a Sin3-independent repression pathway. Genes Dev 2000, I 4(I):45-54.

20. Kao HY, Downes M, Ordentlich P, Evans RM: Isolation of a novel histone deacetylase reveals that class I and class II deacetylases promote SMRT-mediated repression. Genes Dev 2000, I4(1):55-66.

21. Heinzel T, Lavinsky RM, Mullen TM, Soderstrom M, Laherty CD, Torchia J, Yang WM, Brard G, Ngo SD, Davie JR, Seto E, Eisenman RN, Rose DW, Glass CK, Rosenfeld MG: A complex containing 
$\mathrm{N}-\mathrm{CoR}, \mathrm{mSin} 3$ and histone deacetylase mediates transcriptional repression. Nature 1997, 387(6628):43-8.

22. Alland L, Muhle R, Hou H Jr, Potes J, Chin L, Schreiber-Agus N, DePinho RA: Role for N-CoR and histone deacetylase in Sin3mediated transcriptional repression. Nature 1997. 387(6628):49-55.

23. Nagy L, Kao HY, Chakravarti D, Lin RJ, Hassig CA, Ayer DE, Schreiber SL, Evans RM: Nuclear receptor repression mediated by a complex containing SMRT, mSin $3 A$, and histone deacetylase. Cell 1997, 89(3):373-80.

24. Guenther MG, Yu J, Kao GD, Yen TJ, Lazar MA: Assembly of the SMRT-histone deacetylase 3 repression complex requires the TCP-I ring complex. Genes Dev 2002, 16(24):3130-5.

25. Johnson CA, White DA, Lavender JS, O'Neill LP, Turner BM: Human class I histone deacetylase complexes show enhanced catalytic activity in the presence of ATP and co-immunoprecipitate with the ATP-dependent chaperone protein Hsp70. J Biol Chem 2002, 277( I I ):9590-7.

26. Vermeulen M, Carrozza MJ, Lasonder E, Workman JL, Logie C, Stunnenberg HG: In vitro targeting reveals intrinsic histone tail specificity of the Sin3/histone deacetylase and N-CoR/SMRT corepressor complexes. Mol Cell Biol 2004, 24(6):2364-72.

27. Hartman HB, Yu J, Alenghat T, Ishizuka T, Lazar MA: The histonebinding code of nuclear receptor co-repressors matches the substrate specificity of histone deacetylase 3. EMBO Rep 2005, 6(5):445-5I.

28. Jepsen K, Solum D, Zhou T, McEvilly RJ, Kim HJ, Glass CK, Hermanson O, Rosenfeld MG: SMRT-mediated repression of an H3K27 demethylase in progression from neural stem cell to neuron. Nature 2007, 450(7168):415-419.

29. Jepsen K, Gleiberman AS, Shi C, Simon DI, Rosenfeld MG: Cooperative regulation in development by SMRT and FOXPI. Genes Dev 2008, 22(6):740-5.

30. Jepsen $K$, Hermanson O, Onami TM, Gleiberman AS, Lunyak $V$, McEvilly RJ, Kurokawa R, Kumar V, Liu F, Seto E, Hedrick SM, Mandel G, Glass CK, Rose DW, Rosenfeld MG: Combinatorial roles of the nuclear receptor corepressor in transcription and development. Cell 2000, I02(6):753-63.

31. Astapova I, Lee LJ, Morales C, Tauber S, Bilban M, Hollenberg AN: The nuclear corepressor, NCoR, regulates thyroid hormone action in vivo. Proc Natl Acad Sci USA 2008, 105(49): 19544-9.

32. Nofsinger RR, Li P, Hong SH, Jonker JW, Barish GD, Ying H, Chen SY, Leblanc M, Xu W, Pei L, Kang YJ, Nelson M, Downes M, Yu RT, Olefsky JM, Lee CH, Evans RM: SMRT repression of nuclear receptors controls the adipogenic set point and metabolic homeostasis. Proc Natl Acad Sci USA 2008, 105(50):2002I-6.

33. Alenghat T, Meyers K, Mullican SE, Leitner K, Adeniji-Adele A, Avila J, Bucan M, Ahima RS, Kaestner KH, Lazar MA: Nuclear receptor corepressor and histone deacetylase 3 govern circadian metabolic physiology. Nature 2008, 456(7224):997-1000.

34. Hoberg JE, Yeung F, Mayo MW: SMRT derepression by the lkappaB kinase alpha: a prerequisite to NF-kappaB transcription and survival. Mol Cell 2004, I6(2):245-55.

35. Hoberg JE, Popko AE, Ramsey CS, Mayo MW: IkappaB kinase alpha-mediated derepression of SMRT potentiates acetylation of RelA/p65 by p300. Mol Cell Biol 2006, 26(2):457-71.

36. Zhou Y, Gross W, Hong SH, Privalsky ML: The SMRT corepressor is a target of phosphorylation by protein kinase CK2 (casein kinase II). Mol Cell Biochem 200I, 220:I-2.

37. Hong SH, Wong CW, Privalsky ML: Signaling by tyrosine kinases negatively regulates the interaction between transcription factors and SMRT (silencing mediator of retinoic acid and thyroid hormone receptor) corepressor. Mol Endocrinol 1998, | 2(8): ||6|-7|.

38. Hong SH, Privalsky ML: The SMRT corepressor is regulated by a MEK-I kinase pathway: inhibition of corepressor function is associated with SMRT phosphorylation and nuclear export. Mol Cell Biol 2000, 20( I 7):66 I2-25.

39. Jonas BA, Privalsky ML: SMRT and N-CoR corepressors are regulated by distinct kinase signaling pathways. J Biol Chem 2004 279(52):54676-86.

40. McKenzie GJ, Stevenson P, Ward G, Papadia S, Bading H, Chawla S, Privalsky M, Hardingham GE: Nuclear Ca2+ and CaM kinase IV specify hormonal- and Notch-responsiveness. I Neurochem 2005, 93(I): $17 \mid-85$
4I. Yu J, Palmer C, Alenghat T, Li Y, Kao G, Lazar MA: The corepressor silencing mediator for retinoid and thyroid hormone receptor facilitates cellular recovery from DNA double-strand breaks. Cancer Res 2006, 66(18):9316-22.

42. Jeyakumar M, Liu XF, Erdjument-Bromage H, Tempst P, Bagchi MK: Phosphorylation of thyroid hormone receptor-associated nuclear receptor corepressor holocomplex by the DNAdependent protein kinase enhances its histone deacetylase activity. J Biol Chem 2007, 282( I3):93 I2-22.

43. Zhang J, Guenther MG, Carthew RW, Lazar MA: Proteasomal regulation of nuclear receptor corepressor-mediated repression. Genes Dev 1998, I 2( I 2): 1775-80.

44. Frasor J, Danes JM, Funk CC, Katzenellenbogen BS: Estrogen downregulation of the corepressor N-CoR: mechanism and implications for estrogen derepression of $\mathbf{N}$-CoR-regulated genes. Proc Natl Acad Sci USA 2005, 102(37): 13 I 53-7.

45. Stanya KJ, Liu Y, Means AR, Kao HY: Cdk2 and Pin I negatively regulate the transcriptional corepressor SMRT. J Cell Biol 2008, I83(I):49-6I.

46. Lavinsky RM, Jepsen K, Heinzel T, Torchia J, Mullen TM, Schiff R, DelRio AL, Ricote M, Ngo S, Gemsch J, Hilsenbeck SG, Osborne CK, Glass CK, Rosenfeld MG, Rose DW: Diverse signaling pathways modulate nuclear receptor recruitment of $\mathrm{N}-\mathrm{CoR}$ and SMRT complexes. Proc Natl Acad Sci USA 1998, 95(6):2920-5.

47. Graham JD, Bain DL, Richer JK, Jackson TA, Tung L, Horwitz KB: Nuclear receptor conformation, coregulators, and tamoxifen-resistant breast cancer. Steroids. 2000, 65(10II):579-584.

48. Graham JD, Bain DL, Richer JK, Jackson TA, Tung L, Horwitz KB: Thoughts on tamoxifen resistant breast cancer. Are coregulators the answer or just a red herring? I Steroid Biochem Mol Biol 2000, 74(5):255-9.

49. Smith CL, Nawaz Z, O'Malley BW: Coactivator and corepressor regulation of the agonist/antagonist activity of the mixed antiestrogen, 4-hydroxytamoxifen. Mol Endocrinol 1997, II(6):657-66.

50. Ryo A, Liou YC, Wulf G, Nakamura M, Lee SW, Lu KP: PINI is an E2F target gene essential for Neu/Ras-induced transformation of mammary epithelial cells. Mol Cell Biol 2002, 22(15):528I-95.

5I. Neve RM, Sutterluty H, Pullen N, Lane HA, Daly JM, Krek W, Hynes NE: Effects of oncogenic ErbB2 on GI cell cycle regulators in breast tumour cells. Oncogene 2000, I 9(13): I647-56.

52. Varma H, Skildum AJ, Conrad SE: Functional ablation of pRb activates Cdk2 and causes antiestrogen resistance in human breast cancer cells. PLoS ONE 2007, 2(I 2):e I 256.

53. Bao L, Kimzey A, Sauter G, Sowadski JM, KP Lu, Wang DG: Prevalent overexpression of prolyl isomerase Pin I in human cancers. Am J Pathol 2004, 164(5): I727-37.

54. Suizu F, Ryo A, Wulf G, Lim J, Lu KP: Pin I regulates centrosome duplication, and its overexpression induces centrosome amplification, chromosome instability, and oncogenesis. Mol Cell Biol 2006, 26(4): 1463-79.

55. Lam PB, Burga LN, Wu BP, Hofstatter EW, Lu KP, Wulf GM: Prolyl isomerase Pin I is highly expressed in Her2-positive breast cancer and regulates erbB2 protein stability. Mol Cancer 2008, 7:91.

56. Eisold M, Asim M, Eskelinen H, Linke T, Baniahmad A: Inhibition of MAPK-signaling pathway promotes the interactionof the corepressor SMRT with the human androgen receptor and mediatesrepression of prostate cancer cells growth in the presence ofantiandrogens. J Mol Endocrinol 2009, 42(5):429-35. Epub 2009 Feb 17

57. Keeton EK, Brown M: Cell cycle progression stimulated by tamoxifen-bound estrogen receptor-alpha and promoterspecific effects in breast cancer cells deficient in N-CoR and SMRT. Mol Endocrinol 2005, 19(6): 1543-54.

58. Yeh ES, Means AR: PINI, the cell cycle and cancer. Nat Rev Cancer 2007, 7(5):38I-8.

59. Malumbres M, Barbacid M: Cell cycle kinases in cancer. Curr Opin Genet Dev 2007, 17(I):60-5.

60. Schneider G, Reichert M, Saur D, Hamacher R, Fritsch R, Schmid RM: HDAC3 is linked to cell cycle machinery in MiaPaCa2 cells by regulating transcription of skp2. Cell Prolif 2007, 40(4):522-31. 
61. Zhang Y, Tuzova M, Xiao ZX, Cruikshank WW, Center DM: Pro-IL16 recruits histone deacetylase 3 to the Skp2 core promoter through interaction with transcription factor GABP. J Immunol 2008, I 80(I):402-8.

62. Huang W, Tan D, Wang X, Han S, Tan J, Zhao Y, Lu J, Huang B: Histone deacetylase 3 represses pI (INK4b) and p2I(WAFII cip I) transcription by interacting with Sp I. Biochem Biophys Res Commun 2006, 339(I): 165-71.

63. Eot-Houllier G, Fulcrand G, Watanabe Y, Magnaghi-Jaulin L, Jaulin C: Histone deacetylase 3 is required for centromeric H3K4 deacetylation and sister chromatid cohesion. Genes Dev 2008, 22(19):2639-44.

64. Li Y, Kao GD, Garcia BA, Shabanowitz J, Hunt DF, Qin J, Phelan C, Lazar MA: A novel histone deacetylase pathway regulates mitosis by modulating Aurora B kinase activity. Genes Dev 2006, 20(I8):2566-79.

65. Ishii S, Kurasawa Y, Wong J, Yu-Lee LY: Histone deacetylase 3 localizes to the mitotic spindle and is required for kinetochore-microtubule attachment. Proc Natl Acad Sci USA 2008, I 05( I I ):4179-84.

66. Bhaskara S, Chyla BJ, Amann JM, Knutson SK, Cortez D, Sun ZW, Hiebert SW: Deletion of histone deacetylase 3 reveals critical roles in S phase progression and DNA damage control. Mol Cell 2008, 30(I):6I-72.

67. Montgomery RL, Potthoff MJ, Haberland M, Qi X, Matsuzaki S, Humphries KM, Richardson JA, Bassel-Duby R, Olson EN: Maintenance of cardiac energy metabolism by histone deacetylase 3 in mice. J Clin Invest 2008, I I 8( I I):3588-97.

68. Knutson SK, Chyla BJ, Amann JM, Bhaskara S, Huppert SS, Hiebert SW: Liver-specific deletion of histone deacetylase 3 disrupts metabolic transcriptional networks. Embo J 2008 27(7): $1017-28$.

69. Yang XJ, Seto E: The Rpd3/Hda I family of lysine deacetylases: from bacteria and yeast to mice and men. Nat Rev Mol Cell Biol 2008, 9(3):206-18.

Publish with Bio Med Central and every scientist can read your work free of charge

"BioMed Central will be the most significant development for disseminating the results of biomedical research in our lifetime. "

Sir Paul Nurse, Cancer Research UK

Your research papers will be:

- available free of charge to the entire biomedical community

- peer reviewed and published immediately upon acceptance

- cited in PubMed and archived on PubMed Central

- yours - you keep the copyright
BioMedcentral 